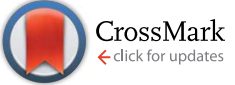

Cite this: RSC Adv., 2017, 7, 10424

\title{
Immobilization of copper ions on chitosan/ cellulose acetate blend hollow fiber membrane for protein adsorption
}

\begin{abstract}
S. S. Shen, ${ }^{a b c}$ J. J. Yang, ${ }^{\text {abc }}$ C. X. Liu ${ }^{d}$ and R. B. Bai ${ }^{\star a b c}$
An affinity membrane was prepared by immobilizing copper ions $\left(\mathrm{Cu}^{2+}\right)$ on chitosan (CS) and cellulose acetate (CA) blend hollow fibers, and the affinity membrane (denoted as CS/CA-Cu) was evaluated for its performance in the adsorption of a model protein, Bovine Serum Albumin (BSA). The analysis indicated that the amount of copper ions coupled on CS/CA-Cu reached around $3.9 \mathrm{mg}$ per g-membrane. The experimental results showed that CS/CA-Cu achieved a high adsorption capacity of the 69 mg-BSA per g-membrane, under the typical solution condition of $\mathrm{pH}$ at 7.4 and ionic strength at $0.12 \mathrm{M}$, with the nonspecific adsorption being as low as less than 15\%. The adsorption isotherm followed the Langmuir model and the adsorption kinetics exhibited both transport-limited and attachment-limited behaviors. $\mathrm{CS} / \mathrm{CA}-\mathrm{Cu}$ also performed favorably in the neutral $\mathrm{pH}$ range and at low ionic strength.
\end{abstract}

Received 5th January 2017

Accepted 27th January 2017

DOI: $10.1039 / \mathrm{c} 7 \mathrm{ra00148g}$

rsc.li/rsc-advances

procedures. However, the major functional groups (usually $-\mathrm{OH})$ in the cellulose related polymer substrates have only limited reactivity and they still require additional chelating agents to facilitate the coupling of the metal ion ligands. For example, glycidyl methacrylate (GMA) has been used to attach a chelator, iminodiacetic acid (IDA), to fabricate the copper coupled IMAM from cellulose acetate (CA) membrane. ${ }^{9}$

In the past 1-2 decades, chitosan (CS, poly- $\beta-(1,4)-2$-amino-2deoxy-D-glucose), which is one of the most abundant polysaccharides on the earth, has attracted significant research and application interest because of its non-toxic, biodegradable and highly biocompatible properties. CS is also abundant in the reactive functional group of $-\mathrm{NH}_{2}$ that can be used as a possible metal ion ligand chelator. ${ }^{10}$ However, due to the poor mechanical strength of CS, most studies have either coated CS on a base membrane ${ }^{11,12}$ or blended it with some matrix polymer, such as cellulose. ${ }^{13,14}$ The coated or blended materials have been found to exhibit enhanced adsorption capacity, ${ }^{15}$ which was attributed to the large number of functional groups from CS, particularly the amino groups that can act as the active sites for the attachment or adsorption of transition metal ions as well as other organic compounds, such as dyes, and proteins. ${ }^{16}$

Liu et al. reported the preparation of a blend hollow fiber membrane from CS and CA, with CA as the matrix polymer and CS as the functional polymer. ${ }^{17,18}$ The prepared blend membranes were found to be highly hydrophilic and porous, have good mechanical strength, and can effectively adsorb transition metal ions, including copper ions. ${ }^{19}$ In the literature, it was reported that copper(II) ions show effective antibacterial action, either alone or in the form of complexes. ${ }^{9,20}$ There are also a few reports on CS-modified CA membrane that exhibited antibacterial properties. ${ }^{21,22}$ 
In this study, an IMAM was prepared by immobilizing copper(II) ions as the metal ion ligand onto the CS/CA blend hollow fiber membrane. The prepared IMAM (denoted as CS/CA-Cu) was examined for its amount of coupled copper ion ligand, the capacity of adsorption for a model protein (Bovine Serum Albumin, or BSA), and the extent of the specific and non-specific adsorption involved, as well as the utilization rate of the coupled copper ion ligand.

\section{Materials and methods}

\subsection{Materials}

CS was obtained from Aldrich, and was indicated as a low molecular weight product. The molecular weight (MW) and deacetylation degree of the CS were determined by GPC (Gel Permeation Chromatography) to be at $75000 \mathrm{~g} \mathrm{~mol}^{-1}$ and by titration at $73.5 \%$, respectively. ${ }^{23} \mathrm{CA}$ was purchased from Fluka and the acetyl content and MW were $40 \%$ and $37000 \mathrm{~g} \mathrm{~mol}^{-1}$ according to the supplier, respectively. Formic acid (98-100 $\mathrm{wt} \%$ ) from Fluka was used as the co-solvent for dissolving both CS and CA together to prepare the blend hollow fiber membrane. Copper sulphate $\left(\mathrm{CuSO}_{4} \cdot 5 \mathrm{H}_{2} \mathrm{O}\right.$, Naealai Tesque Co., Tokyo) was used in the coupling of copper ion ligands on the prepared membrane. Bovine Serum Albumin (BSA), from Sigma and with MW of $67 \mathrm{kDa}$, was used to prepare the protein solution for the adsorption experiments. Other common chemicals as needed were purchased from various suppliers and used without further purification.

\subsection{Preparation of CS/CA-Cu}

The base CS/CA blend hollow fiber membrane was prepared in a similar method described in detail in the literature. ${ }^{19}$ The characteristic structure and morphology of the blend hollow fiber membrane was obtained by scanning electron microscopy (SEM, JEOL JSM-5600, JEOL Ltd., Japan) or field emission scanning electron microscopy (FESEM, JEOL JSM-6700F, JEOL Ltd., Japan). The dimensions of the prepared hollow fiber membrane were also measured using the software supplied with SEM/FESEM.

The CS/CA blend hollow fiber membrane was then immobilized with copper ion ligands. To prepare the IMAM, a $4.4 \mathrm{~g}$ amount of the dry CS/CA was added to $200 \mathrm{~mL}$ of the copper sulphate solution with an initial concentration of $1 \mathrm{~g} \mathrm{~L}^{-1}$ (in terms of $\mathrm{Cu}^{2+}$ ) and an initial $\mathrm{pH}$ of 5 . The mixture in the flask was stirred on a magnetic stirrer at $150 \mathrm{rpm}$ and room temperature $\left(22-23{ }^{\circ} \mathrm{C}\right)$ for $2 \mathrm{~h}$ to allow the $\mathrm{Cu}^{2+}$ ions to react with the amine groups $\left(-\mathrm{NH}_{2}\right)$ of the $\mathrm{CS} / \mathrm{CA}$ membrane to form complexes. The copper ion-coupled hollow fiber membrane was washed thoroughly first with DI water and then with $10 \mathrm{mM}$ phosphate buffer solution (containing $0.12 \mathrm{M} \mathrm{NaCl}$ concentration and having $\mathrm{pH}=7.4$ ). The finally obtained IMAM is denoted as CS/CA-Cu.

The amount of copper ions coupled onto CS/CA-Cu was estimated by stripping it with $500 \mathrm{~mL}$ of $50 \mathrm{mM}$ EDTA solution and then analyzing the concentration of copper ions in the stripping solution using an Inductively Coupled Plasma
Optical Emission Spectrometer (ICP-OES, Perkin-Elmer Optima 3000DV).

\subsection{Protein adsorption experiments}

The adsorption of BSA on the porous hollow fiber membranes (CS/CA-Cu or the control CS/CA) was conducted in batch mode. For the isotherm adsorption study, $1.1 \mathrm{~g}$ amount (dry weight) of the CS/CA-Cu or CS/CA was placed into a $50 \mathrm{~mL}$ of a BSA solution with an initial concentration in the range of 0.4 to $4 \mathrm{~g} \mathrm{~L}^{-1}$. The initial $\mathrm{pH}$ and $\mathrm{NaCl}$ concentration in all solutions were kept constant at 7.4 and $0.12 \mathrm{M}$, respectively. The adsorption mixture was shaken at $150 \mathrm{rpm}$ and room temperature in a water bath shaker for $24 \mathrm{~h}$ to ensure the adsorption equilibrium being fully reached. The BSA concentrations in the solution before and after the adsorption test were determined with a UV-Vis spectrometer at $278 \mathrm{~nm}$. The adsorption amounts of BSA on the CS/ $\mathrm{CA}-\mathrm{Cu}$ or $\mathrm{CS} / \mathrm{CA}$ membrane were calculated by mass balance analysis (adsorption equilibrium data at two other specific $\mathrm{pH}$ values of 4.9 and 6.1 were also obtained under the similar test conditions to $\mathrm{pH} 7.4$ described above).

The effects of the solution $\mathrm{pH}$ and ionic strength on BSA adsorption performance by CS/CA and CS/CA-Cu were also investigated. A $1.1 \mathrm{~g}$ sample (dry weight) of CS/CA-Cu or CS/CA was placed into a $50 \mathrm{~mL}$ BSA solution with an initial concentration of $2.5 \mathrm{~g} \mathrm{~L}^{-1}$. For the effect of the solution $\mathrm{pH}$, the $\mathrm{pH}$ in the solutions was adjusted to a range of 4.9-8.0 using different buffer solutions (10 mM NaAc/HAc for $\mathrm{pH} 4-6$ and $10 \mathrm{mM}$ $\mathrm{NaH}_{2} \mathrm{PO}_{4} / \mathrm{Na}_{2} \mathrm{HPO}_{4}$ for $\left.\mathrm{pH} 6-8\right)$. Owing to the possibility of CS dissolution in acidic solutions and CA degradation under basic conditions, experiments for $\mathrm{pH}$ below 4 and above 8.0 were not conducted. For the effect of the ionic strength, the ionic concentration in the solutions was varied in the range of 0 $1.8 \mathrm{M}$ by adding sodium chloride $(\mathrm{NaCl})$ to the solutions. The ionic strength in the experiments for the $\mathrm{pH}$ effect was fixed at $0.12 \mathrm{M}$, and the $\mathrm{pH}$ in the experiments for examining the ionic strength effect was fixed at 7.4.

For the adsorption kinetic study, a $1.1 \mathrm{~g}$ amount (dry weight) of $\mathrm{CS} / \mathrm{CA}-\mathrm{Cu}$ was added to a flask containing $150 \mathrm{~mL}$ BSA solution at an initial concentration of $2.5 \mathrm{~g} \mathrm{~L}^{-1}$. The solution $\mathrm{pH}$ was controlled at 7.4 and the ionic strength in the solution was set to $0.12 \mathrm{M}$. The mixture was shaken at $150 \mathrm{rpm}$ in a water bath shaker at room temperature. At various desired time intervals, a $3 \mathrm{~mL}$ amount of the solution was sampled from the flask to determine the BSA concentration in the solution.

\section{Results and discussion}

\subsection{Characteristics of $\mathrm{CS} / \mathrm{CA}-\mathrm{Cu}$}

The obtained CS/CA blend hollow fiber membrane had an O.D. and I.D. of 1.13 and $0.67 \mathrm{~mm}$, respectively (wall thickness at around $230 \mu \mathrm{m}$ ). The surface and cross-section morphologies of the hollow fiber membrane are shown in Fig. 1. The hollow fiber membrane generally had a symmetric and spongy structure, and the cross-section was full of highly interconnected pores. This type of porous structure is in fact desirable for affinity membrane because it can provide high process flow rates at low 


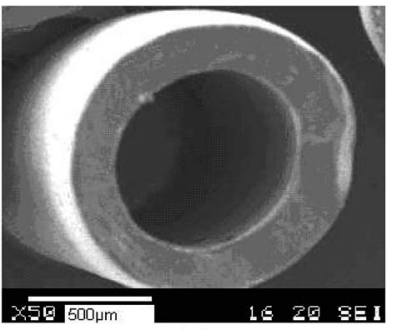

(a)

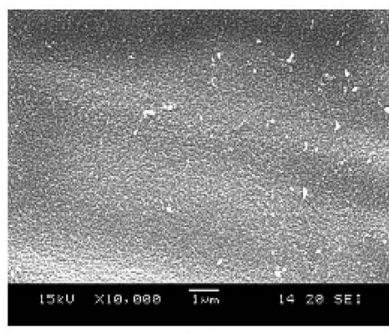

(c)

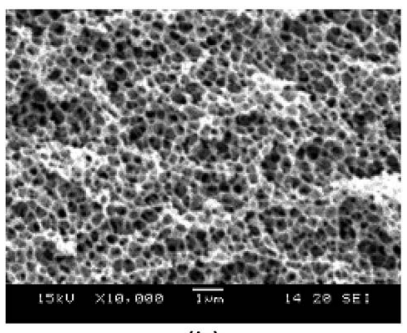

(b)

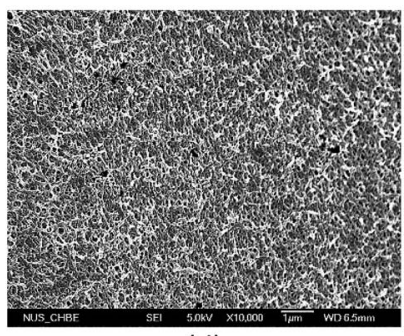

(d)
Fig. 1 Morphology of CS/CA blend hollow fiber membrane. (a) Overall view $\times 50$, (b) cross-section $\times 10000$, (c) outer surface $\times 10000$ and (d) inner surface $\times 10000$.

operation pressures as well as large specific surface areas for high binding capacities. The blend hollow fiber membrane had a relatively denser outer surface, compared to the more porous inner surface, but the pore size (about $70 \mathrm{~nm}$ ) was large enough to allow the free passage of BSA molecules $(<14 \times 4 \times 4 \mathrm{~nm})$ into the internal binding sites of the membrane. The analyses showed that the hollow fiber membrane had a porosity of $79.1 \%$, a specific surface area of $14.1 \mathrm{~m}^{2} \mathrm{~g}^{-1}$, and a CS content of $12 \%$ by weight.

The amount of metal ions coupled on the membrane can be one of the crucial factors affecting the capacity of protein adsorption on IMAMs. In this study, the amount of copper ions coupled on CS/CA-Cu blend hollow fiber membrane was measured and determined to be $3.9 \mathrm{mg}$ per g-membrane (or $32.5 \mathrm{mg} \mathrm{Cu}^{2+}$ per g-CS). ${ }^{19}$

\subsection{BSA adsorption on CS/CA-Cu}

Nonspecific binding is undesirable for affinity separation because it may reduce the separation resolution. The experimental results for the amounts of BSA adsorbed on CS/CA and $\mathrm{CS} / \mathrm{CA}-\mathrm{Cu}$ under different initial BSA concentrations are shown in Fig. 2. The amounts of BSA adsorbed on CS/CA were low, displaying a slight increase with increasing BSA concentrations and achieved a maximum amount of about $9 \mathrm{mg}$ per $\mathrm{g}$ membrane under the conditions examined (BSA concentrations up to $4 \mathrm{~g} \mathrm{~L}^{-1}$ ). The adsorption of BSA on the control CS/CA membrane may be due to the results of nonspecific interactions, such as electrostatic and hydrophobic interactions between BSA and the CS/CA membrane.

To estimate the specific binding of BSA on CS/CA-Cu (i.e., adsorption of BSA via immobilized copper ions), one may take the amount of $9 \mathrm{mg}$-BSA per g-membrane as a maximum estimation of the possible nonspecific binding of BSA on CS/CA-Cu.

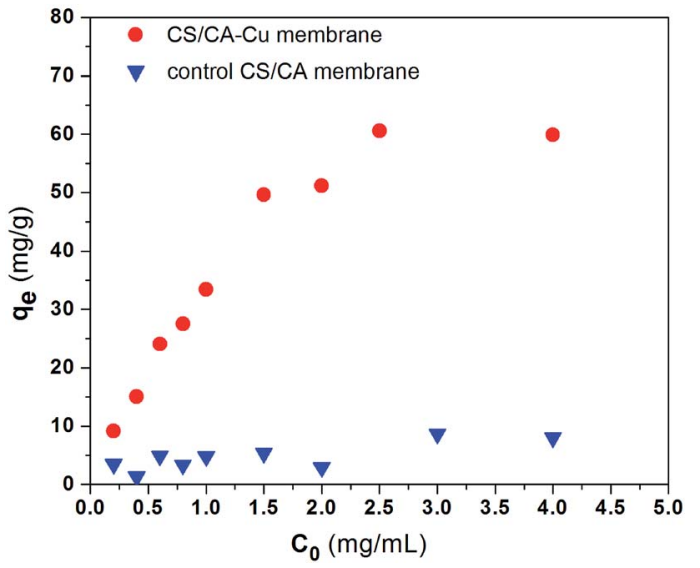

Fig. 2 Adsorption of BSA on the control CS/CA and CS/CA-Cu at pH $7.4\left(C_{0}-\right.$ initial BSA concentration, $q_{\mathrm{e}}-$ equilibrium BSA adsorption amount).

Clearly, from the experimental results in Fig. 2, the amounts of BSA adsorbed on CS/CA-Cu were much greater than those on the control CS/CA, and the difference became more significant when the initial BSA concentration in the solution was increased from 0.2 to $2.5 \mathrm{~g} \mathrm{~L}^{-1}$.

The adsorption amounts appeared to approach a plateau with further increases in the BSA concentrations from 2.5 up to $4 \mathrm{~g} \mathrm{~L}^{-1}$. The maximum adsorption amount on CS/CA-Cu at the plateau level was about $60 \mathrm{mg}$-BSA per g-membrane (or $13.8 \mathrm{mg}$ $\mathrm{mL}^{-1}$ ) in this case (see Fig. 2). Therefore, the specific binding of $\mathrm{BSA}$ on $\mathrm{CS} / \mathrm{CA}-\mathrm{Cu}$ (due to the metal ion ligand) can be deduced as $51 \mathrm{mg} \mathrm{g}^{-1}$ (or $11.7 \mathrm{mg} \mathrm{mL}^{-1}$ ). Hence it can be considered that at least $85 \%$ of the BSA adsorbed on CS/CA-Cu was through the specific binding with the immobilized copper ion ligands. This result of highly specific adsorption should not be surprising if one considers the possible formation of complexes between the numerous imidazole groups of BSA with the copper ion ligands on $\mathrm{CS} / \mathrm{CA}-\mathrm{Cu}$. In the literature, a regenerated cellulose membrane immobilized with copper ions as the ligand was reported to have an adsorption amount of $6.25 \mathrm{mg} \mathrm{mL}^{-1}$ for BSA. $^{24}$

Interestingly, the utilization of the coupled copper ions in this study appears to be much higher than that reported in the literature. The utilization of metal ion ligands has been defined as the amount of protein bond by per unit mass of metal ion ligand. ${ }^{24}$ In this study, the copper ion utilization was calculated to be $15.4 \mathrm{mg}$-BSA per $\mathrm{mg}-\mathrm{Cu}^{2+}$ (or $0.24 \mu \mathrm{M}$-BSA per $\mathrm{mg}-\mathrm{Cu}^{2+}$ ). This is in contrast to $1.5 \mathrm{mg}$-BSA per $\mathrm{mg}^{-\mathrm{Cu}^{2+}}$ (or $0.0226 \mu \mathrm{M}$-BSA per $\left.\mathrm{mg}-\mathrm{Cu}^{2+}\right)$ on microporous polyethylene substrate membrane in ref. 25 or $1.26 \mathrm{mg}$-BSA per $\mathrm{mg}-\mathrm{Cu}^{2+}$ (or $0.019 \mu \mathrm{M}$ BSA per $\mathrm{mg}-\mathrm{Cu}^{2+}$ ) on microporous cellulose substrate membrane in ref. 24 .

It has been generally known that a copper ion can form 6 coordination bonds with surrounding chelators. The participation number of amine groups on CS polymer with a copper ion has been suggested to be in the range of $1-3$, with other coordination sites being occupied by $\mathrm{OH}^{-}$or $\mathrm{H}_{2} \mathrm{O} .{ }^{26}$ Therefore, in general, there are 5 to 3 binding sites (those occupied by $\mathrm{OH}^{-}$ 
or $\mathrm{H}_{2} \mathrm{O}$ ) available for a coupled copper ion on CS/CA-Cu to bind BSA or other proteins. However, for mostly used multidentate chelators, such as iminodiacetic acid (IDA) and nitrilotriacetic acid (NTA) for IMAMs, they are known to provide 3 or 4 binding arms with a metal ion ligand. Therefore, a metal ion ligand on those IMAMs with the conventional chelators can probably have only 3 or 2 free binding sites for protein adsorption. This might explain the high utilization of copper ion ligands on $\mathrm{CS} / \mathrm{CA}-\mathrm{Cu}$ achieved in this study.

\subsection{Effect of pH on BSA adsorption}

In general, the adsorption of protein in immobilized metal ion affinity chromatography is usually governed by the coordination of the metal ion ligand on the IMAMs with the electron-donor atoms or groups exposed on the surface of the proteins to be separated. ${ }^{27,28}$ Hence, the $\mathrm{pH}$ of the liquid phase can have an effect on the binding capacity of IMAMs for protein.

Fig. 3 shows the effects of solution $\mathrm{pH}$ on the adsorption uptake of BSA on CS/CA-Cu and CS/CA obtained from the experiments (ionic strength at $0.12 \mathrm{M} \mathrm{NaCl}$ ). The amount of BSA adsorbed on the CS/CA base membrane decreased slightly with increasing $\mathrm{pH}$. This may be expected because the electrostatic interaction between CS/CA and BSA molecules became less favorable when BSA was negatively charged at $\mathrm{pH}>4.7$ and the amine groups of CS shifted from positively charged at $\mathrm{pH}<6.3$ to neutral or even negatively charged at $\mathrm{pH}>6.3$. However, the amount of BSA binding on $\mathrm{CS} / \mathrm{CA}-\mathrm{Cu}$ increased remarkably from $35 \mathrm{mg} \mathrm{g}^{-1}$ to $58 \mathrm{mg} \mathrm{g}^{-1}$ with the increase in solution $\mathrm{pH}$ from 4.9 to 6.5 , and then stayed at a plateau level with further increases in $\mathrm{pH}$. Therefore, it appears that the adsorption of BSA on CS/CA-Cu was favored under neutral conditions. This condition may be in fact desirable in practical protein separation processes as it can often minimize the need for $\mathrm{pH}$ adjustment.

The $\mathrm{pH}$ dependency of BSA binding onto CS/CA-Cu may be explained by the nature of the interactions between the copper ion ligands and the BSA molecules. The affinity interaction between copper ions (electron acceptors) and imidazole nitrogen (electron donors) of BSA would dominate the specific

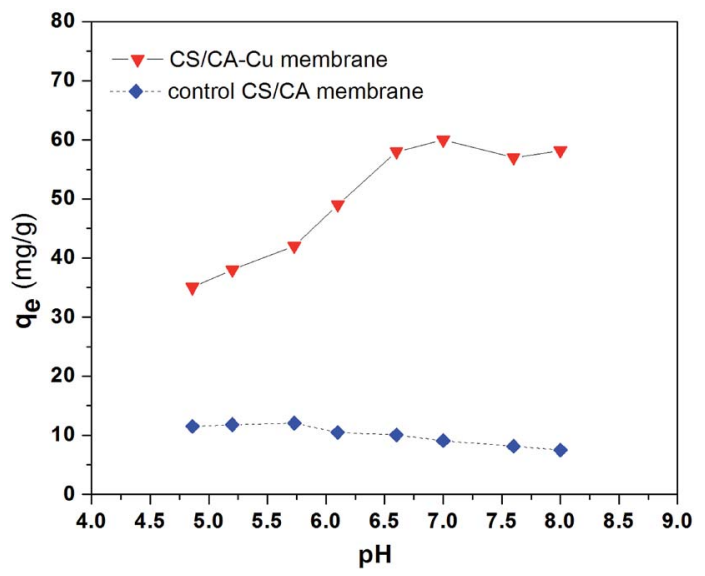

Fig. 3 Effect of $\mathrm{pH}$ on BSA adsorption by CS/CA and CS/CA-Cu. binding. The imidazole nitrogen $\left(\mathrm{p} K_{\mathrm{a}}=6.95\right)$ on BSA is protonated under acidic conditions. Hence, the adsorption uptake amount at $\mathrm{pH} 4.9$ was low because of the weakened electron donor-acceptor interactions due to the existence of a strong electrostatic repulsion force that possibly hindered the approach of BSA to the copper ion ligands on CS/CA-Cu.

With increasing $\mathrm{pH}$ from 4.9 to 7 , the imidazole nitrogen atoms became less protonated and thus the transport of BSA in solution to the copper ions of CS/CA-Cu was favored (due to lower electrostatic repulsion force). This has led to the observed increase in BSA adsorption on CS/CA-Cu with the increase in solution $\mathrm{pH}$. However, with the further increase in the solution $\mathrm{pH}$ above 7 , most imidazole nitrogen atoms were at their deprotonated state, which provided the most favorable condition for BSA adsorption on CS/CA-Cu. On the other hand, more $\mathrm{OH}-$ in the solution led to an increased number of $\mathrm{OH}-$ from the solution being coordinated with the copper ion ligands on $\mathrm{CS} / \mathrm{CA}-\mathrm{Cu}$, which did not favor BSA binding uptake on CS/CA-Cu through affinity interaction. These two counteractions appeared to compensate for each other and the net adsorption amount was maintained at the plateau level in the $\mathrm{pH}$ range from 7 to 8 .

\subsection{Effect of ionic strength on BSA adsorption}

The dependence of BSA adsorption by CS/CA and CS/CA-Cu on the ionic strength of the solution was examined under the condition of $\mathrm{pH} 7.4$ and initial BSA concentration of $2.5 \mathrm{~g} \mathrm{~L}^{-1}$, and the results are shown in Fig. 4. The adsorption uptake amounts of BSA on $\mathrm{CS} / \mathrm{CA}-\mathrm{Cu}$ generally decreased with increasing ionic strength (in terms of $\mathrm{NaCl}$ concentration). Although the changes in the uptake amounts of BSA (about $58 \mathrm{mg} \mathrm{g}^{-1}$ ) were not apparent in the low ionic strength range from 0 to $0.09 \mathrm{M}$, the adsorption uptake amounts of BSA on CS/ CA-Cu decreased significantly with the further increase of the ionic strength from 0.09 to $1.8 \mathrm{M}$ (changed from about $60 \mathrm{mg}$ $\mathrm{g}^{-1}$ at $0.09 \mathrm{M}$ to only about $24.5 \mathrm{mg} \mathrm{g}^{-1}$ at $1.8 \mathrm{M}$; see Fig. 4).

The adsorption uptake amounts of BSA on the control CS/CA membrane also decreased with increasing ionic strength. At an ionic strength of $0.3 \mathrm{M}$ and above, the adsorption uptake amounts of BSA on CS/CA actually decreased to zero. If one

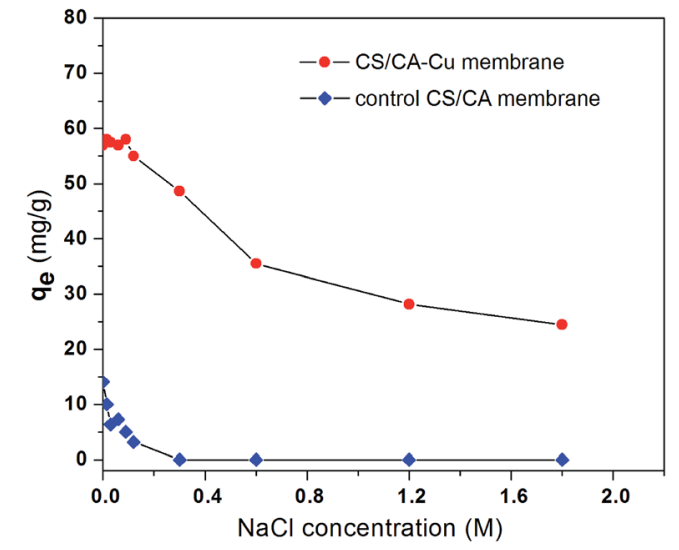

Fig. 4 Effect of ionic strength on BSA adsorption on the control CS/ $\mathrm{CA}$ and the CS/CA-Cu membranes at $\mathrm{pH} 7.4$ and $C_{0}=2.5 \mathrm{~g} \mathrm{~L}^{-1}$. 
takes the amount of BSA adsorbed on CS/CA as the indication of the nonspecific adsorption, the increase in ionic strength in the solution appears to effectively suppress or eliminate the nonspecific binding of BSA on the control CS/CA membrane and thus on $\mathrm{CS} / \mathrm{CA}-\mathrm{Cu}$.

Therefore, the decrease in BSA binding on CS/CA-Cu with increasing ionic strength may be due to two facts. First, the decrease in nonspecific adsorption (or electrostatic interaction) on the CS/CA substrate led to the decreased adsorption of BSA on $\mathrm{CS} / \mathrm{CA}-\mathrm{Cu}$. On the other hand, the high $\mathrm{NaCl}$ concentration in solution would enhance the competition of the coordination sites of the copper ion ligands on CS/CA-Cu by the $\mathrm{Cl}^{-}$anions, which can reduce the extent of the electron donor-acceptor interaction between the copper ion ligands on $\mathrm{CS} / \mathrm{CA}-\mathrm{Cu}$ and the BSA molecules to be adsorbed. ${ }^{29}$ Higher adsorption amounts at lower ionic strengths may be another process advantage for $\mathrm{CS} / \mathrm{CA}-\mathrm{Cu}$ as an IMAM because this makes it unnecessary, as in several other situations, to increase the ionic strength in the solution and enhance the adsorption performance.

\subsection{Adsorption isotherms results}

The two most common adsorption isotherm models are the Langmuir and Freundlich models, which can be given in the forms of eqn (1) and (2), respectively, as below.

$$
\begin{gathered}
q_{\mathrm{e}}=\frac{q_{\mathrm{m}} K c_{\mathrm{e}}}{1+K c_{\mathrm{e}}} \\
q_{\mathrm{e}}=K_{\mathrm{f}} c_{\mathrm{e}^{n}}^{\frac{1}{n}}
\end{gathered}
$$

where $q_{\mathrm{e}}$ is the equilibrium adsorption amounts $\left(\mathrm{mg} \mathrm{g}^{-1}\right) ; q_{\mathrm{m}}$ is the maximum monolayer adsorption amount $\left(\mathrm{mg}^{-1}\right) ; b$ is the Langmuir adsorption equilibrium constant $\left(\mathrm{mL} \mathrm{mg}^{-1}\right) ; C_{\mathrm{e}}$ is the equilibrium concentration of adsorbate in solution $\left(\mathrm{mg} \mathrm{mL}^{-1}\right)$; $1 / n$ is the Freundlich intensity parameter (dimensionless); and $K_{\mathrm{f}}$ is Henry's law constant, $\left(\mathrm{mg} \mathrm{g}^{-1}\right)\left(\mathrm{mL} \mathrm{mg}^{-1}\right)^{-1 / n}$. The Langmuir isotherm model assumes that the adsorbed layer is one molecule in thickness, all adsorption sites have equal energies and enthalpies of adsorption, and no interactions exist between the adsorbed molecules. The Freundlich model is based on an assumption of adsorption on heterogeneous surfaces and also possibly in a multi-layer adsorption pattern. ${ }^{29}$

Eqn (1) and (2) are used to fit the experimental results in Fig. 2 and the fitted results for the adsorption isotherm data of BSA on $\mathrm{CS} / \mathrm{CA}-\mathrm{Cu}$ are shown in Fig. 5. Fitting analysis was conducted by applying the non-linear regression method for $q_{\mathrm{e}}$ versus $C_{\mathrm{e}}$ through Origin Software 6.0. The parameter values determined from the fitting analysis are given in Table 1 . It can be found that the Langmuir model fits the experimental data well; however, the Freundlich model is much less satisfactory. The results therefore indicate that BSA adsorption on $\mathrm{CS} / \mathrm{CA}-\mathrm{Cu}$ was dominated by chemical interaction and probably in a monolayer pattern. This is expected as, in the early discussion, $85 \%$ of the adsorbed BSA on $\mathrm{CS} / \mathrm{CA}-\mathrm{Cu}$ was deduced to be through specific binding (i.e., chemical interaction). BSA has an isoelectrical point at $\mathrm{pH}$ 4.9. Under the experimental condition of $\mathrm{pH} 7.4$, BSA was negatively

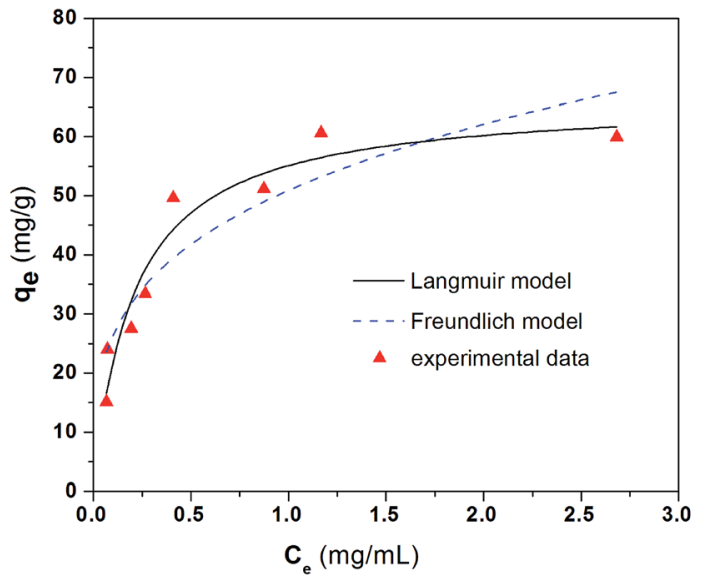

Fig. 5 Adsorption isotherm results for BSA on CS/CA-Cu at $\mathrm{pH} 7.4$.

\begin{tabular}{|c|c|c|c|c|}
\hline \multirow[b]{2}{*}{ Model } & \multirow[b]{2}{*}{$\mathrm{pH}$} & \multicolumn{3}{|c|}{ Adsorption isotherm parameter } \\
\hline & & $R^{2}$ & $q_{\mathrm{m}}\left(\mathrm{mg} \mathrm{g}^{-1}\right)$ & $K\left(\mathrm{~mL} \mathrm{mg}^{-1}\right)$ \\
\hline \multirow[t]{3}{*}{ Langmuir } & 4.9 & 0.98 & 39.78 & 3.32 \\
\hline & 6.1 & 0.98 & 53.10 & 4.71 \\
\hline & 7.4 & 0.93 & 66.35 & 4.89 \\
\hline & & \multicolumn{3}{|c|}{ Adsorption isotherm parameter } \\
\hline Model & $\mathrm{pH}$ & $R^{2}$ & $\begin{array}{l}K_{\mathrm{f}}\left(\mathrm{mg} \mathrm{g}^{-1}\right) \\
\left.(\mathrm{mL} \mathrm{mg})^{-1}\right)^{-1 / n}\end{array}$ & $1 / n$ \\
\hline \multirow[t]{3}{*}{ Freundlich } & 4.9 & 0.86 & 28.12 & 0.28 \\
\hline & 6.1 & 0.92 & 40.45 & 0.28 \\
\hline & 7.4 & 0.85 & 50.91 & 0.27 \\
\hline
\end{tabular}

Table 1 Isotherm model parameters at different $\mathrm{pH}$

charged. Hence, multi-layer adsorption may be unlikely due to the electric repulsion between the adsorbed BSA and BSA in the solution to be further adsorbed. The maximum adsorption amount $\left(q_{\mathrm{m}}\right)$ and the adsorption equilibrium constant $K$ obtained from the Langmuir model fitting calculation were $66.35 \mathrm{mg} \mathrm{g}^{-1}$ and $4.89 \mathrm{~mL} \mathrm{mg}{ }^{-1}$, respectively. The predicted adsorption capacity of $66.35 \mathrm{mg} \mathrm{g}^{-1}$ is very close to the experimental maximum value of $60 \mathrm{mg} \mathrm{g}^{-1}$ shown in Fig. 2 .

The adsorption isotherm data were also evaluated at two other $\mathrm{pH}$ values of 4.9 and 6.1; the results are shown in Fig. 6. The parameter values obtained by the non-linear regression of eqn (1) and (2) to the experimental data are also included in Table 1. Again, these results also showed that the Langmuir model had a better fit to the experimental data than the Freundlich model. The predicted maximum adsorption amounts, $q_{\mathrm{m}}$, from the Langmuir model are $39.78 \mathrm{mg} \mathrm{g}^{-1}$ for $\mathrm{pH}$ 4.9 and $53.10 \mathrm{mg} \mathrm{g}^{-1}$ for $\mathrm{pH} 6.1$ in comparison to the $66.35 \mathrm{mg}$ $\mathrm{g}^{-1}$ for $\mathrm{pH} 7.4$ mentioned early. These predicted maximum adsorption amounts indicate a similar change trend in the adsorption performance with the effect of solution $\mathrm{pH}$ discussed in Section 3.3. 


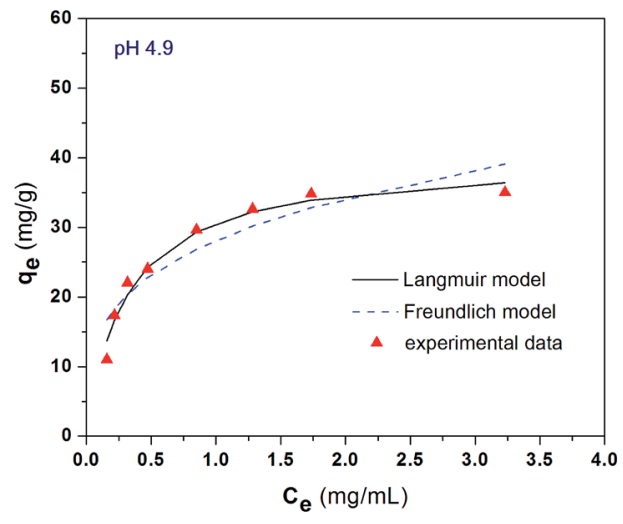

(a)

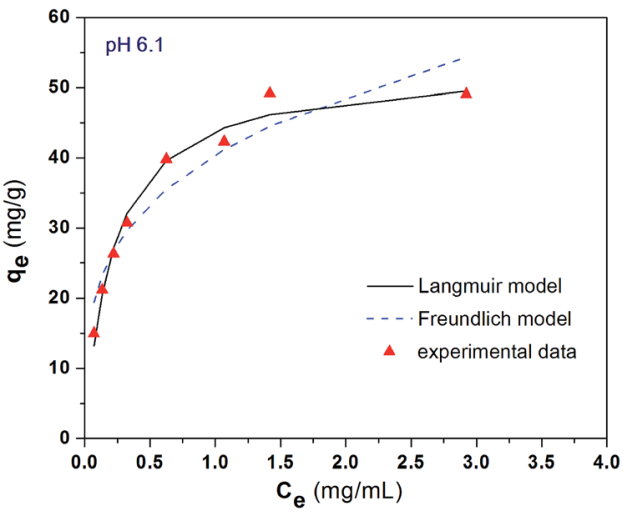

(b)

Fig. 6 Equilibrium adsorption results of BSA on CS/CA-Cu at $\mathrm{pH} 4.9$ (a) and $\mathrm{pH} 6.1$ (b) under room temperature.

\subsection{Adsorption kinetic behaviour}

The kinetic changes in the BSA concentrations in the bulk solution with adsorption time from a typical experiment are presented in Fig. 7. The adsorption took about $10 \mathrm{~h}$ to reach equilibrium. Two processes may be involved in the adsorption of BSA on CS/CA-Cu: (a) the transport of BSA from the bulk solution to the surface of $\mathrm{CS} / \mathrm{CA}-\mathrm{Cu}$ and (b) the attachment of BSA on CS/CA-Cu. In the initial stage, the surface of CS/CA-Cu was relatively free of BSA and the BSA molecules that arrived

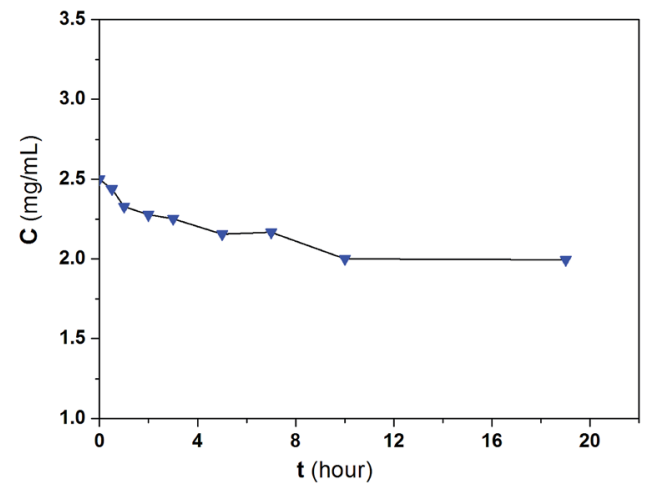

Fig. 7 Kinetic adsorption results of BSA on CS/CA-Cu. at the surface of CS/CA-Cu may attach instantly to it. Hence, the adsorption rate may be dominated by the diffusion of BSA from the bulk solution to the surface of $\mathrm{CS} / \mathrm{CA}-\mathrm{Cu}$ in this case.

Based on the Fickian diffusion law, the amount of adsorption by diffusion-controlled dynamics as a function of time may be given as follows: ${ }^{30}$

$$
q_{t}=k_{\mathrm{d}} t^{0.5}
$$

where $q_{t}$ is the amount of BSA adsorbed per unit weight of the hollow fibers $\left(\mathrm{mg} \mathrm{g}^{-1}\right)$ at time $t(\mathrm{~h})$, and $k_{\mathrm{d}}$ is a system constant $\left(\mathrm{mg}\left(\mathrm{g} \mathrm{t}^{-0.5}\right)^{-1}\right)$. Eqn (3) indicates that under a diffusioncontrolled transport mechanism, $q(t)$ versus $t^{0.5}$ would follow a linear relationship.

Fig. 8a shows a plot of $q(t)$ versus $t^{0.5}$ for the experimental results in Fig. 7. A linear relationship of $q(t)$ against $t^{0.5}$ is indeed observed in the initial period of time. The results suggest the existence and the importance of diffusion-controlled transport mechanisms in BSA adsorption on $\mathrm{CS} / \mathrm{CA}-\mathrm{Cu}$, at least in the beginning of the process.

On the other hand, the adsorption rate may also be controlled by the attachment of BSA on CS/CA-Cu, particularly in the later stages when $\mathrm{CS} / \mathrm{CA}-\mathrm{Cu}$ may be gradually saturated with previously adsorbed BSA. For attachment controlled adsorption, the amount of adsorption may be given by the Lagergren model as follows: ${ }^{31}$

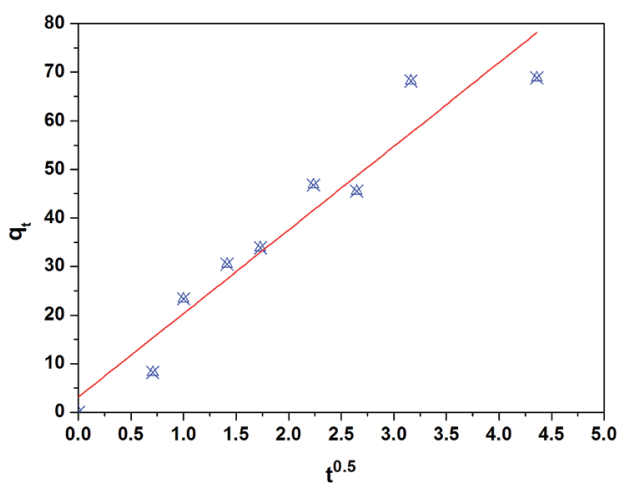

(a)

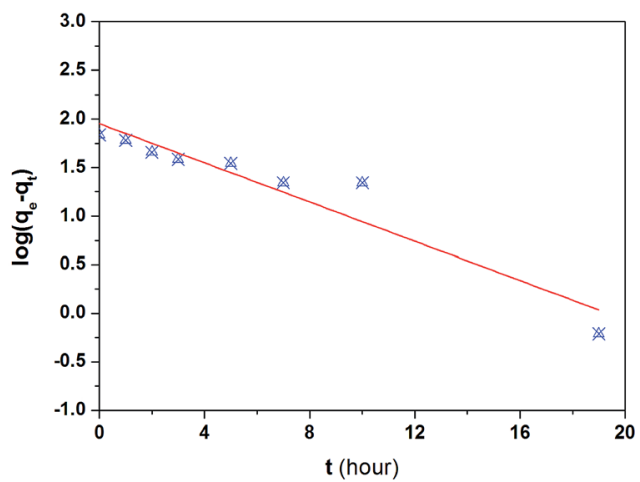

(b)

Fig. 8 Fitted results of typical adsorption kinetic models: (a) diffusioncontrolled adsorption kinetics model and (b) attachment-controlled adsorption kinetic model. 


$$
\log \left(q_{\mathrm{e}}-q_{t}\right)=\log \left(q_{\mathrm{e}}\right)-\frac{K_{1}}{2.303} t
$$

where $q_{\mathrm{e}}, q_{t}$ and $t$ have the same definition as before, and $K_{1}$ is a constant.

The plot of $\log \left(q_{\mathrm{e}}-q_{t}\right)$ vs. $t$ in terms of eqn (4) for the experimental results shown in Fig. 7 is presented in Fig. 8b. An approximate linear relationship indicated in eqn (4) is observed for almost the entire adsorption process, suggesting that the attachment process was indeed very important in the adsorption kinetics of BSA on CS/CA-Cu, particularly when the kinetic study was conducted at a relatively high BSA concentration in this case.

\section{Conclusion}

The CS/CA blend hollow fiber membrane can be used directly for the immobilization of metal ion ligands to prepare IMAM. The obtained CS/CA blend hollow fiber membrane achieved an immobilized amount of copper ions of $3.9 \mathrm{mg} \mathrm{\textrm {g } ^ { - 1 }}$ membrane. The prepared $\mathrm{CS} / \mathrm{CA}-\mathrm{Cu}$ showed an adsorption capacity of $69 \mathrm{mg}$-BSA per $\mathrm{g}$ membrane at $\mathrm{pH} 7.4$ and a $\mathrm{NaCl}$ concentration of $0.12 \mathrm{M}$ under room temperature. At least $85 \%$ of the adsorbed BSA was probably through specific interactions by the copper ion ligands on $\mathrm{CS} / \mathrm{CA}-\mathrm{Cu}$ with the BSA molecules. The utilization of the coupled copper ion ligand reached as high as $15.4 \mathrm{mg}$-BSA per $\mathrm{g}-\mathrm{Cu}^{2+}$. The adsorption isotherm was well described by the Langmuir isotherm model. The adsorption kinetics appeared to be affected by the transport-controlled mechanism in the initial stage but attachment-controlled mechanism throughout the entire process. In the $\mathrm{pH}$ range of 4.9-8.0 and ionic strength of 0.0-1.8 M examined, BSA adsorption on the prepared CS/CA$\mathrm{Cu}$ IMAM showed the best performance at around neutral $\mathrm{pH}$ values (6.5-8) and at low ionic strength $(<0.09 \mathrm{M})$, attributed to the reduced repulsive electrostatic interaction or the reduced effect of competing anions, which favored the affinity interaction of BSA with the copper ion ligands. The study shows the potential prospects of using CS/CA hollow fiber membrane to prepare IMAMs for protein separation. Further investigation will be done in the enhancement of the adsorption amount and in the establishment of the dynamic separation performance.

\section{Acknowledgements}

The financial support from the National Natural Science Foundation of China (No. 51478282), Suzhou Key Lab of Separation and Purification Materials \& Technologies (SZS201512), and The Open Project of Jiangsu Key Laboratory of Environmental Science and Engineering (No. ZD131206) are greatly appreciated.

\section{References}

$1 \mathrm{~J}$. Zhu and G. Sun, Facile fabrication of hydrophilic nanofibrous membranes with an immobilized metal- chelate affinity complex for selective protein separation, ACS Appl. Mater. Interfaces, 2014, 6(2), 925-932.

2 G. Bayramoglu and M. Y. Arica, Poly(methyl methacrylateglycidiyl methacrylate) film with immobilized iminodiacetic acid and $\mathrm{Cu}(\mathrm{II})$ ion: for protein adsorption, Fibers Polym., 2012, 13(10), 1225-1232.

3 S. Bhattacharjee, J. L. Dong, Y. D. Ma, S. Hovde, J. H. Geiger, G. L. Baker and M. L. Bruening, Formation of high-capacity protein-adsorbing membranes through simple adsorption of poly(acrylic acid)-containing films at low pH, Langmuir, 2012, 28(17), 6885-6892.

4 C. I. Chen, Y. M. Ko, W. L. Lien, Y. H. Lin, I. T. Li, C. H. Chen, C. J. Shieh and Y. C. Liu, Development of the reversible PGA immobilization by using the immobilized metal ion affinity membrane, J. Membr. Sci., 2012, 401, 33-39.

5 C. I. Chen, Y. M. C. J. Shieh and Y. C. Liu, Direct penicillin G acylase immobilization by using the self-prepared immobilized metal affinity membrane, J. Membr. Sci., 2011, 380, 34-40.

6 J. H. Wu, Z. Wang, W. T. Yan, Y. Wang, J. X. Wang and S. C. Wang, Improving the hydrophilicity and fouling resistance of RO membranes by surface immobilization of PVP based on a metal-polyphenol precursor layer, $J$. Membr. Sci., 2015, 496, 58-69.

7 H. Nagami, H. Umakoshi, T. Kitaura, G. L. Thompson, T. Shimanouchi and R. Kuboi, Development of metal affinity-immobilized liposome chromatography and its basic characteristics, Biochem. Eng. J., 2014, 84, 66-73.

8 Y. M. Ke, C. I. Chen, P. M. Kao, H. B. Chen, H. C. Huang, C. J. Yao and Y. C. Liu, Preparation of the immobilized metal affinity membrane with high amount of metal ions and protein adsorption efficiencies, Process Biochem., 2010, 45(4), 500-506.

9 S. Asapu, S. Pant, C. L. Gruden and I. C. Escobar, An investigation of low biofouling copper-charged membranes for desalination, Desalination, 2014, 338, 17-25.

10 V. K. Thakur and S. I. Voicu, Recent advances in cellulose and chitosan based membranes for water purification: a concise review, Carbohydr. Polym., 2016, 146, 148-165.

11 T. Chakrabarty and V. K. Shahi, Modified chitosan-based, $\mathrm{pH}$-responsive membrane for protein separation, $R S C A d v$., 2014, 4(95), 53245-53252.

12 K. Liu, L. H. Chen, L. L. Huang and Y. N. Lai, Evaluation of ethylenediamine-modified nanofibrillated cellulose/ chitosan composites on adsorption of cationic and anionic dyes from aqueous solution, Carbohydr. Polym., 2016, 151, 1115-1119.

13 H. P. S. A. Khalil, C. K. Saurabh, A. S. Adnan, M. R. Nurul Fazita, M. I. Syakir, Y. Davoudpour, M. Rafatullah, C. K. Abdullah, M. K. M. Haafiz and R. Dungani, A review on chitosan-cellulose blends and nanocellulose reinforced chitosan biocomposites: properties and their applications, Carbohydr. Polym., 2016, 150, 216-226.

$14 \mathrm{H}$. Celebi and A. Kurt, Effects of processing on the properties of chitosan/cellulose nanocrystal films, Carbohydr. Polym., 2015, 133, 284-293. 
15 E. Salehi, P. Daraei and A. A. Shamsabadi, A review on chitosan-based adsorptive membranes, Carbohydr. Polym., 2016, 152, 419-432.

16 A. Li, R. J. Lin, C. Lin, B. Y. He, T. T. Zheng, L. B. Lu and Y. Cao, An environment-friendly and multi-functional absorbent from chitosan for organic pollutants and heavy metal ion, Carbohydr. Polym., 2016, 148, 272-280.

17 C. X. Liu and R. B. Bai, Preparation of chitosan/cellulose acetate blend hollow fibers for adsorptive performance, $J$. Membr. Sci., 2005, 267, 68-77.

18 C. X. Liu and R. B. Bai, Preparing highly porous chitosan/ cellulose acetate blend hollow fibers as adsorptive membranes: effect of polymer concentrations and coagulant compositions, J. Membr. Sci., 2006, 279, 336-346.

19 C. X. Liu and R. B. Bai, Adsorptive removal of copper ions with highly porous chitosan/cellulose acetate blend hollow fiber membranes, J. Membr. Sci., 2006, 284, 313-322.

20 G. Mary, S. K. Bajpai and N. Chand, Copper(II) ions and copper nanoparticles-loaded chemically modified cotton cellulose fibers with fair antibacterial properties, J. Appl. Polym. Sci., 2009, 113, 757-766.

21 S. Waheed, A. Ahmad, S. M. Khan, S. Gul, T. Jamil, A. Islam and T. Hussain, Synthesis, characterization, permeation and antibacterial properties of cellulose acetate/polyethylene glycol membranes modified with chitosan, Desalination, 2014, 351, 59-69.

22 A. G. Boricha and Z. V. P. Murthy, Preparation of $\mathrm{N}, \mathrm{O}$-carboxymethyl chitosan/cellulose acetate blend nanofiltration membrane and testing its performance in treating industrial wastewater, Chem. Eng. J., 2010, 157, 393-400.
23 X. Jiang, L. Chen and W. Zhong, A new linear potentiometric titration method for the determination of deacetylation degree of chitosan, Carbohydr. Polym., 2003, 54, 457-463.

24 C. Y. Wu, S. Y. Suen, S. C. Chen and J. H. Tzeng, Analysis of protein adsorption on regenerated cellulose-based immobilized copper ion affinity membranes, $J$. Chromatogr., 2003, 996, 53-70.

25 H. Iwata, K. Saito, S. Furusaki, T. Sugo and J. Okamato, Adsorption characteristics of an immobilized metal affinity membrane, Biotechnol. Prog., 1991, 7, 412-418.

26 M. Rhazia, J. Desbrières, A. Tolaimate, M. Rinaudob, P. Votterod and A. Alagui, Contribution to the study of the complexation of copper by chitosan and oligomers, Polymer, 2002, 43, 1267-1276.

27 E. K. M. Ueda, P. W. Gout and L. Morganti, Current and prospective applications of metal ion-protein binding, $J$. Chromatogr., 2003, 988, 1-23.

28 R. S. Pasquinelli, R. E. Shepherd, R. R. Koepsel, A. Zhao and M. M. Ataai, Design of affinity tags for one-Step protein purification from immobilized zinc columns, Biotechnol. Prog., 2000, 16, 86-91.

29 N. Li and R. B. Bai, Copper adsorption on chitosan-cellulose hydrogel beads: behaviors and mechanisms, Sep. Purif. Technol., 2005, 42, 237-247.

30 M. Alkan, M. Dogan, Y. Turhan, O. Demirbas and P. Turan, Adsorption kinetics and mechanism of maxilon blue 5G dye on sepiolite from aqueous solutions, Chem. Eng. J., 2008, 139, 213-223.

$31 \mathrm{X}$. Zhang and R. B. Bai, Mechanisms and kinetics of humic acid adsorption to chitosan-coated granules, J. Colloid Interface Sci., 2003, 264, 30-38. 